\title{
Design research of RFID-based brand clothing logistics storage management system
}

\author{
Cuijuan Liu' ${ }^{1}$,Weilan Jia $^{1}$ \\ ${ }^{1}$ Shijiazhuang Information Engineering Vocational College, Shijiazhuang, 050000, China
}

Keywords: RFID technology; brand clothing; logistics storage management system; design research

\begin{abstract}
. market demand for clothing industry changes quickly, so clothing logistics storage management must have a swift response and be flexible. In particular, it is significant for brand clothing logistics to own a scientific and rational storage management system. It can improve rapid response ability of logistics and enhance competitiveness of brand clothing industry. On this basis, this paper carries out design research of brand clothing logistics storage management system in allusion to application of RFID technology in brand clothing logistics storage management.
\end{abstract}

\section{Introduction}

Market demand for clothing industry changes quickly, so clothing logistics storage management must have a swift response and be flexible. RFID technology can be applied in brand clothing logistics storage, such as goods sorting, goods exhibition, storage, inventory verification, exwarehouse, sorting and information processing ${ }^{[1]}$. It can improve working efficiency and accuracy of brand clothing logistics storage.

\section{Current situation of brand clothing logistics}

As a fashion industry, clothing industry is characterized by short period, small batch, multiple varieties and quick delivery. Since clothing commodities own diversity and seasonality, logistics support system of clothing industry also needs to keep high smoothness and efficiency. From the perspective of functions, modern clothing logistics mainly utilizes information technology and automation technology to complete basic processes of clothing products "sales", “stock", "storage" and "delivery" on the basis of traditional logistics. "Sales" refers to ex-warehouse and delivering goods. In actual sales, e-order and customers should be confirmed first. "Stock” refers to receiving clothing goods, in-warhorse and inspection. "Storage" refers to storing clothing products. There are many goods storage ways, including stereoscopic warehouse and plane warehouse. "Delivery" refers to distribution. Since clothing products have numerous specifications and varieties, clothing products also have diversified market demands. Compared with items in traditional industries, clothing products need to distribute clothing products under diversified market demands.

\section{Importance of brand clothing logistics storage management}

In the whole clothing supply chain, storage management gives play to important effects. As a bond linking consumers and producers, clothing storage management experiences manual stage, mechanization stage, automation stage and intelligent information integration stage. Under normal conditions, clothing logistics storage management mainly includes goods storage, goods sorting, goods delivery and goods ex-warehouse. In goods storage management, the weight, variety, , size of goods, the requirements for temperature and humidity as well as basic delivery law are main factors influencing goods storage management.

\section{RFID technology can assist realization of visual logistics storage management}

RFID technology is radio frequency identification technology and belongs to non-contact automatic identification technology. It mainly uses radio-frequency signal and utilizes space coupling to reach 
non-contact information transfer and identification. In the identification process, manual intervention is not needed. In logistics field, RFID technology is mainly applied to track, identify, position and manage storage of goods. Usually, RFID system is mainly composed of electronic tag, reader-writer, computer control terminal and antenna etc.

In the process of clothing logistics storage, RFID technology can assist realization of visual logistics storage management ${ }^{[2]}$. RFID electronic tag is installed on the external packing of goods. When goods pass the transfer station and transportation inspection station, electronic tag reader can carry out a series of work for brand clothing without contact such as rapidly reception of goods, stock, in-warehouse and ex-warehouse, which saves time and achieves visual management. During transportation, the electronic tag on the reader will utilize telephone wire and satellite to transmit relevant information to the database of the transport department. When goods passes an inspection station, the data in the database will be updated. When the electronic tag arrives at the destination, the database will be closed. If the owner wants to know the accurate position of goods, the owner can visit the webpage according to his power ${ }^{[3]}$.

\section{Design of RFID-based brand clothing logistics storage management system}

\section{Design of reception sub-system}

As RFID technology is continuously promoted and applied, clothing suppliers will use RFID tag and paste it on the packing. But some goods have no RFID tag on the packing. To better adapt future development and reach use requirements, there are mainly two processes during receiving goods. In actual implementation process, selection can be made according to specific conditions.

\section{No RFID tag is pasted on brand clothing packing}

When the dispatch bill information is sent to the end system, the goods use plan will be prearranged. When the goods arrive, actual arrival of goods will be typed in the end system, when the end system will generate RFID data and transmit reception command. After receiving the command of end system, RFID system will generate RFID tag according to specific data. Then, receiving clerks hang the tag on goods and utilize wireless network to retrieve idle forklift. The end system will transmit the receiving order. Then, the front-end system receives the reception order. The driver uses the forklift to carry the goods to the check-waiting area. When passing the antenna field, specific goods information about destination, freight bill, arrival address and order details will be automatically sent to the end system. At this moment, the end system owns specific arrival information data. After goods enter the check-waiting area, the driver can use mobile devices to read goods allocation and goods information and transmit the data to the front-end system. After receiving data, the front-end system will check the data according to system command. If the data are consistent, the drive will be instructed to transport goods to the specified check-waiting area. After the data verified, the front-end system will transmit final data to the end system. After the end system receives data, it will update and mark the specific position of the current container. After the operation is finished, the driver presses down OK button and the forklift will return to the queue of empty forklifts and wait for next command,

\section{There is RFID tag on the goods received}

After receiving the delivery note, the end system will pre-arrange use plan of goods and generate reception command according to specific requirements. After the good arrive, the end system will utilize wireless network to retrieve idle forklifts and send commands for reception note. After the front-end system receives the reception note, the driver will drive the forklift to transport the goods to the check-waiting area. When the goods pass the forklift, the fixed reader-writer will read the tag in batch and gain all information about the goods including delivery address, goods No. and order details. Then, the information data will be transported to the end system. The end system gains specific goods information ${ }^{[4]}$. After the goods enter the check-waiting area, the driver can use mobile devices to read goods allocation and transmit the data to the front-end system. The front-end system checks the data collected according to system command. If the data are consistent, the driver will be instructed to transport the goods to the check-waiting area. Then, the front-end system sends the confirmed data to the end system. The end system marks the specific position of the container 
according to the data received. After the operation is completed, the driver presses down OK button, and the end system will automatically return the forklift to idle forklift and wait for next command of the system.

\section{Design of stock sub-system}

Generally, warehouse types are difference, and the stock taking ways are also different. The requirements for stick are different, too. During taking stock, the working process and equipment are different. Stock process package needs to point out requirements of checking three-dimensional warehouse and plane warehouse.

\section{Checking three-dimensional warehouse}

The antenna is installed at both sides of the stocker and connected to a fixed reader-writer with the feedback line. The reader-writer utilizes reader-writer and backstage management for communication. After the stocker is positioned to checking goods allocation, the reader-writer is controlled via network. Then, the data in the tray tag are read. The data are transmitted to backstage management system through wireless network. Since the specific quantity of commodities borne by the tray is recorded in the tray tag, RFID technology can reach automatic division of area and taking stock without manual intervention. The stock accuracy is high, and the stock speed is fast ${ }^{[6]}$.

\section{Manual checking of plane warehouse}

The end system will first generate specific stock taking command according to specific business requirement and transmit the stock taking note to the front-end system. After receiving the stock taking note, stock taking work utilizes mobile devices to read the tag in the goods allocation, gains physical count quantity of goods and transmits the quantity to the front-end system. The front-end system checks whether the data are consistent according to system command. If the data are consistent, the stock taking personnel use mobile devices to read the bar code of the goods and send the bar code to the front-end system. Then, the front-end system checks the data collected according to the command. If the data are consistent, the stock taking personnel will be instructed to check the specific quantity. After the stock taking is over, actual goods quantity is typed in the system. The front-end system checks physical count quantity and the quantity of objects and instructs stock taking personnel to recheck according to corresponding stock measurement. After stock settlement is finished, the front-end system sends specific data to the end system. Then, the end system updates according to the data received.

\section{Design of in-warehouse subsystem}

According to relevant business requirements, the end system generates in-warehouse command. The end system retrieves the idle forklift through wireless network and then transmits specific inwarehouse work. After the front-end system receives in-warehouse work note, it applies mobile devices to read container tag or goods tag code in the check-waiting area and transmit it to the frontend system. The front-end system checks the data collected according to system command. If the data are consistent, the driver is instructed to transport the goods to the appointed position. After the driver enters the warehouse area, the driver uses mobile devices to read the tag and transmit the specific data to the front-end system. The front-end system checks the data according to system command. If the data are consistent, the driver is instructed to transport the goods to the position. Meanwhile, RFID system updates the data in the goods tag. After the operation is finished, the driver presses down OK button. This shows in-warehouse is finished. The operation result will be transmitted to the end system from the front-end system through wireless network. After receiving relevant data, the end system will update.

\section{Design of ex-warehouse subsystem}

Firstly, warehouse management personnel will gain the command of ex-warehouse from the warehouse management system, know specific work details, formulate ex-warehouse plan and prepare ex-warehouse sheet. The ex-warehouse sheet is downloaded to the terminal of the forklift. The forklift driver drives the forklift to the specified position and then uses handheld reader-writer to read and write position storage tag. After making sure the system saving is correct, the drivers takes out the specified brand clothing from the saved position. After the brand clothing is taken out, RFID tag is installed on the automatic identification device. Then, the system identifies which 
customer the brand clothing belongs to. After the goods are transported to the warehouse outlet, the mobile device is used to scan goods information . after the information is checked, ex-warehouse operation is conducted as required.

\section{Information management sub-system}

To ensure system operation safety and system expansibility, it is necessary to provide scientific and reasonable safety protection tools. In system information management process, the system mainly maintains and corrects system operation parameters, allocates limits of authority, adds, deletes and modifies the data sheet. Besides, the system has perfect login procedure. Different operating personnel have different limits of authority. All limits of authority are set by the system administrator. One-key recovery and backup functions are provided in the system, which effectively business data continuity and safety. The practice proves that the system can timely feed back relevant information through monitoring and analyzing storage information data and makes information flow and logistics reach synchronous state. This can make brand clothing logistics storage management more intelligent and automatic.

\section{Conclusions}

This paper aims at application of RFID technology in brand clothing logistics storage management for design research of brand clothing logistics storage management system and proposes design scheme of goods reception, stock, in-warehouse, ex-warehouse and information processing systems. It can improve quick reaction capability of logistics and enhance competitiveness of brand clothing. In one word, this paper puts forward scientific and reasonable solutions in the aspect of brand clothing logistics storage management system which improves functions and working efficiency of brand clothing logistics storage management.

\section{References:}

[1] Liu Cuijuan, Liu Baoxue, Analysis and research of brand clothing logistics storage [J]. Jiangsu Commercial Forum, 2012,(12)

[2] Liu Cuijuan, Ji Wen, Design of storage logistics monitoring system under visualization technology [J]. Logistics Technology, 2014 (1)

[3] Xie Meng, Qian Xiaonong, Huo Yunfu, Exploration of logistics management of clothing enterprises [J]. Market Modernization, 2007,(01): 491-492

[4] Sunil Chopra, Supply chain management [M]. translated by Chen Rongqiu, Beijing: Renmin University of China Press, 2008,(03): 186-187

[5] Wang Zhongmin, Internet of Things [M]. Beijing: China Standards Press, 2004,(01): 235-236

[6] Xu Qi, RFID-based storage and delivery intelligent management of clothing supply chain [J]. Journal of Textile Research, ,2010,(09): 31-35 